\title{
Effect of Overground Walking and Treadmill Exercise on Walking Speed and Walking Ability in Elderly
}

\author{
Theresia Chandra Tania Novy, Vitriana, Sunaryo Barki Sastradimaja, Irma Ruslina Defi \\ Department of Physical Medicine and Rehabilitation, Faculty of Medicine, Universitas Padjadjaran-Dr. Hasan \\ Sadikin General Hospital
}

Abstract
Objective: To compare the effect of overground walking and treadmill exercise
on walking speed and ability in elderly from week to week.
Methods: This study was conducted in 6 weeks to 18 elderly at Panti Wreda
Karitas and Nazareth Bandung (September-December 2011). They were divided
into two groups; overground walking exercise group and treadmill group. Walking
speed and ability was measured using 10 meter walk test and 6 minute walk test
consecutively.
Results: Both group walking speed was improved after 1 and 2 weeks exercise
(p=0.019 and p=0.050), consecutively. Walking ability in the overground
and treadmill group was improved after 1 and 3 weeks exercise (p=0.019
and p=0.009), consecutively. Overground walking group showed greater
improvement in walking speed and ability after 3 weeks exercise (p=0.008 and
p=0.017) consecutively.
Conclusions: Three weeks overground walking exercise improves walking speed
and ability better than treadmill exercise.
Received:
November 28, 2012
Revised:
$\begin{aligned} & \text { March 13, 2013 } \\ & \text { ability, walking speed }\end{aligned}$
$\begin{aligned} & \text { Accepted: } \\ & \text { January 31, 2013 }\end{aligned}$

\section{Introduction}

There are two causal factors for the risk of falling in elderly: intrinsic factor (physical and neuropsychiatric conditions, decreased vision and hearing, neuromuscular changes, walking pattern, and postural reflect due to aging process) and extrinsic factor (medicines taken, walking-aid, and unsupportive/dangerous environment). ${ }^{1-3}$ Poor balance and abnormality of walking pattern contribute to $10-15 \%$ of the risk of falling in elderly.

Normal walk parameters include velocity or speed, i.e. the walking speed in meter second; stride length or cycle length, i.e. the length from one heel strike to another heel strike of the same foot; stride time, i.e. distance between a heel strike of a foot and another heel strike of the other foot; and cadence or walking speed,

\footnotetext{
Correspondence:

Theresia Chandra Tania Novy, Department of Physical Medicine and Rehabilitation, Faculty of Medicine, Universitas Padjadjaran-Dr. Hasan Sadikin General Hospital Jl. Pasteur No. 38, Bandung, Indonesia e-mail: tctnovyss@gmail.com
}

i.e. the walking speed in number of steps per minute. ${ }^{4}$

Walking quality is one of the factors that will determine the quality of life. However, in elderly, this function can be disrupted. Walking quality includes locomotor instability and walking ability. In general, the locomotor instability in elderly is caused by decreased muscle mass, strength, power, joint movement area scope, and flexibility. These result in changes in terms of elderly walking pattern (decreased stride length, stance phase and expanded double support, as well as decreased stride symmetry), ${ }^{5}$ which leads to increased energy expenditure and decreased ability for long distance walk. The elderly muscle strength and endurance that are under the threshold will limit the elderly to ambulate outside the house. Therefore, the elderly will tend to stay home which less activities, causing further decrease in the functional capacity and higher risk for fall. $2,3,6$

The elderly stride length is shorter than that of adults but the elderly cadence is relatively similar to adults and even sometimes smaller than adults, making the elderly walking speed 
inside and outside a room lower than those of the adults. A 70-year-old elderly walks with a speed of $1.1 \pm 0.2 \mathrm{~m} / \mathrm{sec}$ for females and $1.2 \pm 0.2$ $\mathrm{m} / \mathrm{sec}$ for male when a person should walk with a minimum speed of $1.4 \mathrm{~m} / \mathrm{sec}$ to be effective enough to walk in an environment such as to cross a street safely. ${ }^{2,6}$

Exercise interventions can be provided to deal with reduced locomotor functions among elderly, which include exercises to improve muscle mass and durability, strength, power, joint movement area scope, flexibility, balance, reaction time, and endurance. Walking is an aerobic exercise that has been promoted to improve physical and cognition functions in elderly. This exercise is usually done by using two methods, i.e. treadmill and over ground walking. ${ }^{6-8}$

Overground walking exercise is carried out by walking on a flat surface with or without visual and auditory aids. Meanwhile, treadmill is one of the instruments used to exercise a dynamic walk in one place. Treadmill exercise using the forced use-method is intended to improve step length and walking speed. The treadmill movement will regulate the movement of both legs appropriately. ${ }^{6,7}$

Some studies have been performed to look at the differences between walking exercises using treadmill and overground walking in terms of the biomechanical outputs and walking patterns in elderly. However, only one study had compared the effect of treadmill and overground exercise on elderly daily activities, especially walking. ${ }^{5-7}$ Marsh et al. ${ }^{8}$ from the Department of Health and Exercise Science, Wake Forest University, North Carolina, United State, performed a study on treadmill and overground exercise effects in 23 elderly people. At the end of the study, Marsh et al. ${ }^{8}$ found that the walking speed of the overground walking group was higher that the treadmill ground, and the overground walking group also showed more appreciation and interest on the exercise compared to the treadmill group.

There are only a few studies of overground walking and treadmill exercise effects on elderly walking speed and ability available. Therefore, our present study specifically compares the overground walking and treadmill effects on elderly walking speed and ability in Indonesia which is monitored weekly using 10 meter walking test and 6 minute walking test in order to determine the exact time when the exercise effects appear and to identify which exercise is better between the this two exercises.

\section{Methods}

This study received ethical approval from the Ethical Committee of Dr. Hasan Sadikin General Hospital and every participant has signed an informed consent. The subject includes all elderly in Karitas and Nazareth nursing home during the period of September-December 2011 who met the inclusion criteria and were not excluded based on the exclusion criteria. The inclusion criteria include 60-90 years old males and females who are able to understand verbal and written instructions, able to sign the instructions (Mini Mental State Evaluation/ MMSE = 24-30), able to walk without any walking aid/orthosis, have minimum motoric strength of 4 for lower limbs, are cooperative

Tabel 1 Before and After Walking Speed in Overground Walking Group

\begin{tabular}{|c|c|c|c|}
\hline \multicolumn{4}{|c|}{ Walking speed (in meters/second) } \\
\hline \multirow[t]{3}{*}{ Week of observation } & \multicolumn{2}{|c|}{ Overground walking group } & \multirow{3}{*}{ p value*) } \\
\hline & Before $(n=9)$ & After $(n=9)$ & \\
\hline & Mean \pm SD & Mean $\pm S D$ & \\
\hline $1^{\text {st }}$ week & $1.08 \pm 0.18$ & $1.28 \pm 0.20$ & 0.058 \\
\hline $2^{\text {nd }}$ week & $1.08 \pm 0.18$ & $1.33 \pm 0.26$ & 0.019 \\
\hline $3^{\text {rd }}$ week & $1.08 \pm 0.18$ & $1.43 \pm 0.22$ & 0.001 \\
\hline $4^{\text {th }}$ week & $1.08 \pm 0.18$ & $1.47 \pm 0.13$ & 0.001 \\
\hline $5^{\text {th }}$ week & $1.08 \pm 0.18$ & $1.56 \pm 0.19$ & 0.001 \\
\hline $6^{\text {th }}$ week & $1.08 \pm 0.18$ & $1.71 \pm 0.19$ & $<0.001$ \\
\hline
\end{tabular}

*) Dependent $t$ test

SD: standard deviation 
and willing to participate in the study, and able to perform the walking training. The exclusion criteria include cardiovascular problems such as unstable angina pectoris and congestion heart disorder, neuromuscular disorders, and musculoskeletal disorders, making it impossible to perform the exercise procedures. Elderly with a history of falling during the last 6 months was also excluded.

There were 24 subjects who met the inclusion and exclusion criteria. All subjects were divided randomly using the block permutation method into two groups, (A) overground walking group and (B) treadmill group. Each group consisted of 12 people. During the process, 6 people dropped out (DO) (25\%), which included 3 people from each group. One person from group A dropped out because the person did not want to continue the exercise while 2 people from the same group dropped due to sickness. In group B, one person dropped out because of unwillingness to continue the exercise, another one dropped out because of exhaustion and the last person dropped out due to sickness.

The overground training given in this study included walking training on flat surface floor without any visual or auditory aids. ${ }^{8}$ The training was performed according to the participant's ability with a maximum of 60 minutes per exercise, 3 times a week for 6 weeks, with the following details:

1. Week I (to improve step length): participant was walking with the most comfortable step length, by taking as little step as possible and maintaining one foot as long as possible in the air.
2. Week II-IV (to increase speed): when the comfortable step length was achieved, the speed was increased to a Rating of Perceived Excertion (RPE) of $12-13$ or $60 \%$ of the maximum heart rate.

The treadmill exercise was performed on a treadmill which is one of the tools used to exercise dynamic walking that enable enforced walking with certain speed and can be adjusted according to the user's need. ${ }^{7}$ The participants performed the exercise according to the participant's ability with a maximum of 60 minutes per exercise, 3 times a week for 6 weeks, using the following treadmill exercise procedure:

1. The participant was standing on a treadmill with hands on the hand support.

2. Week I (to improve step length): Treadmill was set on the lowest speed ( $0.5 \mathrm{~km} / \mathrm{hour})$ and a constant elevation degree of $0^{\circ}$ during the study. The participants were asked to walk according to the treadmill speed, then the speed was increased to reach the most comfortable speed for the participant to walk by taking as little step as possible and maintaining one foot as long as possible in the air.

Week II-VI (to increase speed): when the most comfortable step length was achieved, the speed was increased to RPE $12-13$ or $60 \%$ of the maximum heart rate.

Before the exercises, all participants were measured for the blood pressure and the heart rate. The exercise was started by stretching the quadriceps, hamstring, anterior tibia and gastrocnemius muscles

Table 2 Before and After Walking Speed in Treadmill Group

\begin{tabular}{lccc}
\hline & \multicolumn{2}{c}{ Walking speed (in meters/second) } \\
\multirow{2}{*}{ Week of observation } & \multicolumn{2}{c}{ Treadmill group } & \\
\cline { 2 - 3 } & \multicolumn{2}{c}{ Before $(\mathbf{n}=9)$} & \multirow{2}{*}{ p value*) } \\
\cline { 2 - 3 } & Mean \pm SD & Mean \pm SD & \\
\hline$n^{1 \text { st }}$ week & $1.04 \pm 0.22$ & $1.16 \pm 0.22$ & 0.050 \\
$2^{\text {nd }}$ week & $1.04 \pm 0.22$ & $1.13 \pm 0.17$ & 0.017 \\
$3^{\text {rd }}$ week & $1.04 \pm 0.22$ & $1.15 \pm 0.15$ & 0.003 \\
$4^{\text {th }}$ week & $1.04 \pm 0.22$ & $1.15 \pm 0.20$ & $<0.001$ \\
$5^{\text {th }}$ week & $1.04 \pm 0.22$ & $1.22 \pm 0.17$ & $<0.001$ \\
$6^{\text {th }}$ week & $1.04 \pm 0.22$ & $1.24 \pm 0.16$ & 0.003 \\
\hline
\end{tabular}

*) Dependent $t$ test

SD: standard deviation 
Table 3 Differences of Changing Walking Speed between Overground Walking Group and Treadmill Group

\begin{tabular}{|c|c|c|c|c|c|c|c|}
\hline \multirow{3}{*}{$\begin{array}{c}\text { Time of } \\
\text { observation }\end{array}$} & \multicolumn{6}{|c|}{ Change of walking speed ( $\Delta$, in meters/second) } & \multirow{3}{*}{ p value*) } \\
\hline & \multicolumn{3}{|c|}{ Overground walking Group $(n=9)$} & \multicolumn{3}{|c|}{ Treadmill group $(n=9)$} & \\
\hline & Mean \pm SD & Median & Range & Mean $\pm S D$ & Median & Range & \\
\hline $\begin{array}{l}\text { Beginning of } 1^{\text {st }} \\
\text { week }\end{array}$ & $0.20 \pm 0.17$ & 0.30 & $-0.18-0.60$ & $0.17 \pm 0.15$ & 0.18 & $-0.13-0.43$ & 0.442 \\
\hline $\begin{array}{l}\text { Beginning of } 2^{\text {nd }} \\
\text { week }\end{array}$ & $0.25 \pm 0.20$ & 0.12 & $-0.05-0.66$ & $0.89 \pm 0.14$ & 0.08 & $-0.13-0.37$ & 0.114 \\
\hline $\begin{array}{l}\text { Beginning of } 3^{\text {rd }} \\
\text { week }\end{array}$ & $0.35 \pm 0.21$ & 0.35 & $0.05-0.72$ & $0.11 \pm 0.10$ & 0.13 & $-0.07-0.31$ & 0.008 \\
\hline $\begin{array}{l}\text { Beginning of } 4^{\text {th }} \\
\text { week }\end{array}$ & $0.39 \pm 0.21$ & 0.35 & $0.15-0.84$ & $0.10 \pm 0.08$ & 0.12 & $-0.07-0.21$ & 0.002 \\
\hline $\begin{array}{l}\text { Beginning of } 5^{\text {th }} \\
\text { week }\end{array}$ & $0.48 \pm 0.28$ & 0.34 & $0.17-1.07$ & $0.17 \pm 0.07$ & 0.20 & $0.04-0.24$ & 0.010 \\
\hline $\begin{array}{l}\text { Beginning of } 1^{\text {st }} \\
\text { week }\end{array}$ & $0.53 \pm 0.30$ & 0.61 & $0.21-1.16$ & $0.19 \pm 0.10$ & 0.19 & $0.02-0.34$ & 0.002 \\
\hline
\end{tabular}

*) Independent $t$ test

SD: standard deviation

Outcome measurements are performed by:

1. Six minute walking test for walking ability. The participant's walking ability to walk for 6 minutes ( 6 minute walking test) which is measured by the distance achieved (meter). ${ }^{9}$

2. Ten meter walking test for walking speed. Walking speed that is measured by 10 meter walking test with a distance unit that is divided by the time $(\mathrm{m} / \mathrm{sec}) .{ }^{10-12}$

Every week, the 10 meter walking test and 6 minute walking test were performed by both groups on the same day with 10 minute time interval for resting between the tests.

\section{Results}

Statistical test results on the overground walking and treadmill group characteristic comparisons, including age, body mass index (BMI), duration of stay in the nursing home, gender and education, show that both groups are homogenous. The normality test with the Shapiro Wilks test for a sample size of less than 50 people shows that the walking speed change in the overground walking and treadmill groups is normally distributed, and the walking ability in the overground walking and treadmill groups is not normally distributed.
To test the comparison between the speed and ability of the elderly in the overground walking and treadmill groups before and after the study, the bivariate analysis was performed using the dependent t-test because the data are normally distributed. The independent t-test was used for the bivariate analysis to compare the walking speed change of the overground walking and treadmill groups because the data are normally distributed, and for the comparison of walking ability change of the overground walking and treadmill groups the Mann Whitney test was used because the data are not normally distributed.

Walking speed comparison between elderly in overground walking and treadmill groups for six week exercise can be observed in Table 1 and Table 2, showing increased walking speed starting two weeks after the overground walking exercise was started $(p=0.019)$ and since one week after the treadmill exercise was started $(p=0.050)$. Table 3 shows that the overground walking group has better walking speed increase compared to the treadmill group after three weeks of exercise $(p=0.008)$.

The comparison between walking ability of the elderly overground walking and treadmill groups after six weeks shows that the walking ability improvement was observed since one week after the overground walking exercise was 
Table 4 Before and After Walking Ability in Overground Walking Group

\begin{tabular}{lccc}
\hline & \multicolumn{2}{c}{$\begin{array}{c}\text { Walking ability (in meters) } \\
\text { Overground walking group }\end{array}$} & \multirow{2}{*}{ p value*) } \\
\cline { 2 - 3 } Week of observation & Before $(\mathbf{n}=9)$ & Mean \pm SD & \\
\cline { 2 - 3 } & $314.89 \pm 14.33$ & $369.55 \pm 66.31$ & 0.019 \\
\hline$n^{1 \text { st }}$ week & $314.89 \pm 14.33$ & $374.89 \pm 50.43$ & 0.003 \\
$2^{\text {nd }}$ week & $314.89 \pm 14.33$ & $390.00 \pm 58.55$ & 0.003 \\
$3^{\text {rd }}$ week & $314.89 \pm 14.33$ & $400.67 \pm 49.09$ & $<0.001$ \\
$4^{\text {th }}$ week & $314.89 \pm 14.33$ & $408.94 \pm 48.11$ & $<0.001$ \\
$5^{\text {th }}$ week & $314.89 \pm 14.33$ & $419.11 \pm 44.01$ & $<0.001$ \\
$6^{\text {th }}$ week & & \\
\hline
\end{tabular}

*) Dependent $t$ test

SD: standard deviation

started $(p=0.019)$ and since three weeks after the treadmill exercise was started $(p=0.009)$ (Table $4,5)$. The overground walking group has better walking ability improvement than the treadmill group after three weeks of exercise $(p=0.017)$ (Table 6).

\section{Discussion}

Walking is an excellent aerobic exercise mode and has been promoted to improve physical and cognition functions in elderly. For some elderly, walking can be performed comfortably at home, in the mall or park environment. Walking function declines due to the age factor, making the overground walking and treadmill walking exercises useful to improve the elderly's aerobic capacity.

A significant aerobic capacity improvement will be seen in 4-6 weeks of an aerobic exercise. Marsh et al. ${ }^{8}$ had performed a study on treadmill and overground walking impact towards elderly physical functions and attitude. In this study, both groups performed 6 weeks exercises $(18$ sessions) which is similar to the present study, i.e. 6 weeks with 3 exercises per week (18 sessions), were also applied in this study.

In elderly, female walking speed is slower than the male's because the males are taller than the females and they have more and stronger muscle. In addition, males walk more compared to females. ${ }^{13-16}$ Furthermore, elderly walking speed is affected by education level. ${ }^{15,16}$ These confounding factors was already eliminated by the statistic test results that show the fact that both groups are homogeneous.
Changes in walking characteristics among elderly lead to decreased walking speed. ${ }^{2,5}$ This is in agreement with the present study results showing that the overground walking group average walking-speed is $1.08 \mathrm{~m} / \mathrm{sec}$ and the treadmill group is $1.04 \mathrm{~m} / \mathrm{sec}$ (Table 1 and 2 ).

The increased walking speed after two weeks of overground walking exercise $(p=0.019)$ and after one week of treadmill exercise $(p=0.050)$. The overground walking group had better speed that the treadmill group after three weeks of exercise $(p=0.008)$ (Table 3$)$. This is related to the fact that the treadmill forced the participants to follow its rotation speed. Sohn et al. ${ }^{17}$ studied about the possibility of increased stress because of walking on a treadmill. Likewise, Marsh et $a l^{8}$ found that the overground walking group showed more appreciation and interest to the exercise compared to the treadmill group so they performed the exercise better. In this study, the participants also completed a questionnaire that, later on, was analyzed statistically with the results show that the elderly in Karitas and Nazareth nursing home in Bandung preferred the overground walking exercise to the treadmill although there was no significant difference in the subjective perception based on the exercise given and when the group was asked to perform other group's exercise, no significant difference in subjective perception between the overground walking and treadmill exercise was found. This may lead to the overground walking group trains better in the second weeks and, comparing to the treadmill group, results in better speed increase in the overground walking group.

From week to week, the overground walking group speed was higher than that of the treadmill 
group, and still showed an increase after the sixth week, whereas the treadmill group started to reach plateau after the sixth week. Therefore, a longer study is needed to see the time when the walking speed from the overground walking and treadmill exercises reach the plateau and then maintained according to the elderly's needs for daily activities. In addition, it is observed that the overground walking group reached the minimum walking speed needed for safe ambulation (1.4 $\mathrm{m} / \mathrm{sec}$ ) in the third week and still increases in the following weeks, while the treadmill group had not reached the minimum walking speed needed for safe ambulation.

The results of this study are similar to those of a former study performed by Marsh et al. ${ }^{8}$ which stated that the elderly walking speed after overground walking exercises is higher when it is compared to the treadmill exercise group after 6 weeks (18 sessions) (t $(22)=-8.54, p<0.001$, $t(22)=-10.87, p=0.001$, respectively). However, the former researchers did not examine the elderly walking speed change improvement in each exercise group from week to week.

The statistic test results used dependent t-test with 95\% confidence level (Table 4). This shows that statistically there is a significant difference in elderly walking ability in Karitas and Nazareth nursing home in Bandung before and after the overground walking exercise was performed for one week with $p=0.019$, and after the second week and afterwards with $\mathrm{p} \leq 0.05$. In addition, Table 5 shows a significant difference in elderly walking ability in Karitas and Nazareth nursing home in Bandung before and after the treadmill exercise that started to appear after three weeks of exercise with $p=0.009$ and after the fourth week with $p \leq 0.05$. Furthermore, it can be seen that the walking ability improvement in both groups still continue after the sixth week of the exercise and the statistic test using Mann Whitney test with $95 \%$ confidence level shows a significant difference between the overground walking and treadmill exercise effects on elderly walking ability improvement after three weeks of exercise with $p=0.017(p \leq 0.05)$ and after the fourth week and afterwards with $p \leq 0.05$ (table $6)$, so a longer study is needed to see when the elderly walking ability starts to be stable in both groups.

This study shows that the overground walking group has better subjective perception regarding the exercise compared to the treadmill group, albeit statistically insignificant. This makes the elderly in the overground walking group performs better than those in the treadmill group, leading to higher walking ability improvement in this group.

Muscle adaptation towards aerobic exercises such as walking includes improved capillaries, increased number of mitochondria and size improvement as well as early improvement in oxidative enzyme activities (in 7-10 days). This adaptation increases the muscle capacity to extract oxygen from arteries for metabolism. A significant aerobic capacity improvement will be seen in 4-6 weeks of aerobic exercise. Aerobic capacity improvement in this study is noticed from improved elderly walking speed and ability after two weeks and one week of the overground walking exercise and also in the treadmill group after one week and three weeks of exercise.

Several previous studies have been performed to compare walking temporal parameter, joint kinematics, and muscle activation pattern in treadmill and overground walking, often leading

Tabel 5 Before and After Walking Ability in Treadmill Group

\begin{tabular}{|c|c|c|c|}
\hline \multirow{3}{*}{ Week of observation } & \multicolumn{2}{|c|}{$\begin{array}{c}\text { Walking ability (in meters) } \\
\text { Treadmill group }\end{array}$} & \multirow{3}{*}{ p value*) } \\
\hline & Before $(n=9)$ & After $(n=9)$ & \\
\hline & Mean $\pm S D$ & Mean $\pm S D$ & \\
\hline $1^{\text {st }}$ week & $282.94 \pm 57.69$ & $290.83 \pm 55.91$ & 0.183 \\
\hline $2^{\text {nd }}$ week & $282.94 \pm 57.69$ & $298.38 \pm 41.98$ & 0.053 \\
\hline $3^{\text {rd }}$ week & $282.94 \pm 57.69$ & $307.50 \pm 55.97$ & 0.009 \\
\hline $4^{\text {th }}$ week & $282.94 \pm 57.69$ & $311.27 \pm 60.64$ & 0.014 \\
\hline $5^{\text {th }}$ week & $282.94 \pm 57.69$ & $321.27 \pm 62.23$ & 0.002 \\
\hline $6^{\text {th }}$ week & $282.94 \pm 57.69$ & $325.94 \pm 64.41$ & 0.001 \\
\hline
\end{tabular}

*) Dependent $t$ test

SD: standard deviation 


\begin{tabular}{|c|c|c|c|c|c|c|c|}
\hline \multirow{3}{*}{$\begin{array}{c}\text { Time of } \\
\text { observation }\end{array}$} & \multicolumn{6}{|c|}{ Change of walking ability ( $\Delta$, in meters) } & \multirow{3}{*}{ p value*) } \\
\hline & \multicolumn{3}{|c|}{ Overground walking group $(n=9)$} & \multicolumn{3}{|c|}{ Treadmill group $(n=9)$} & \\
\hline & Mean $\pm S D$ & Median & Range & Mean $\pm S D$ & Median & Range & \\
\hline $\begin{array}{l}\text { Beginning of } \\
1^{\text {st }} \text { week }\end{array}$ & $54.66 \pm 50.25$ & 49.0 & $-27.5-132.5$ & $7.89 \pm 6.23$ & 9.00 & $-18.0-30.0$ & 0.566 \\
\hline $\begin{array}{l}\text { Beginning of } \\
2^{\text {nd }} \text { week }\end{array}$ & $60.00 \pm 42.41$ & 52.5 & $2.5-129.5$ & $15.44 \pm 10.47$ & 10.0 & $0.5-64.5$ & 0.233 \\
\hline $\begin{array}{l}\text { Beginning of } \\
3^{\text {rd }} \text { week }\end{array}$ & $75.11 \pm 52.08$ & 65.5 & $-18.5-137.5$ & $24.56 \pm 21.42$ & 18.0 & $0.5-75.0$ & 0.017 \\
\hline $\begin{array}{l}\text { Beginning of } \\
4^{\text {th }} \text { week }\end{array}$ & $85.78 \pm 45.31$ & 71.0 & $18.0-140.0$ & $28.33 \pm 27.26$ & 25 & $2.5-93.0$ & 0.002 \\
\hline $\begin{array}{l}\text { Beginning of } \\
5^{\text {th }} \text { week }\end{array}$ & $94.06 \pm 45.72$ & 81.0 & $33.0-154.0$ & $38.33 \pm 25.73$ & 39.0 & $7.5-95.0$ & 0.002 \\
\hline $\begin{array}{l}\text { Beginning of } \\
6^{\text {th }} \text { week }\end{array}$ & $104.22 \pm 42.70$ & 94.0 & $54.0-163.0$ & $43.00 \pm 28.09$ & 42 & $11.5-107.5$ & 0.001 \\
\hline
\end{tabular}

*) Mann Whitney test

SD: standard deviation

to contradictory results. A study done by Lee and Hidler ${ }^{6}$ on healthy subjects without any gait problem showed that, generally, the temporal parameter and kinematic pattern of treadmill or overground walking are quite same. Riley et al. ${ }^{17}$ suggested that the kinematic and kinetic differences between treadmill and overgound walking exercises are less than three degrees and can be ignored. Tulchin et al. ${ }^{18}$ evaluated ankle movement in treadmill walking and overground walking with results showed that the segmented multi feet kinematics of both methods do not show any significant difference. Sohn et al. ${ }^{19}$ stated that the walking kinematics on treadmill and overground walking were very similar, even though the value difference in every joint was significant $(p \leq 0.05)$ with a general differences of less that $3^{\circ}$. The walking energy expenditure on treadmill is significantly higher than that of the overground walking and it is thought that there is an increased stress in treadmill exercise induced by the treadmill track. Improvement or change resulted from the training on a treadmill is not always transferable to the daily walking activity. Readjustment is needed to be included into the daily walking activity for the elderly, especially in terms of identifying obstacles and changing the strategy for walking inside and outside the house in a daily basis ${ }^{20}$ and, for this study, in six minute walking test and ten meter walking test. When walking on a treadmill, the muscle activation pattern and, later, joint moments and powers change while the body tries to maintain the extremity kinematics and spatiotemporal parameter of the relatively constant walking pattern. This explanation could help us to understand why overground walking gave better results compare with treadmill. In summary, the elderly walking speed and walking ability are better after overground walking exercise compared to the treadmill. The effect of exercise was seen at three weeks after exercise given.

\section{References}

1. Felsenthal G, Lehman JA, Stein BD. Principles of geriatric rehabilitation. In: Braddom RL, editor. Handbook of physical medicine and rehabilitation. $3^{\text {th }}$ ed. Philadelphia: Saunders An
Imprint of Elsevier Inc.; 2007. p. 910-28.

2. Lemaire E. Biomechanics of elderly gait. 2011 [cited 24 Januari 2011]. Available at http://www. ispo.ca/member/files/lemaire-gait.ppt. 
3. Tinetti ME. Preventing falls in elderly persons. $\mathrm{N}$ Eng J Med. 2006;348:42-9.

4. Masdeu JC, Sudarsky L, Wolfson L, eds. Gait disorders of aging, falls and therapeutic strategies. $1^{\text {st }}$ ed. Philadelphia: Lippincott-Raven Publishers; 1997.

5. Rose J, Gamble JG. Human walking. $1^{\text {st }}$ ed. Philadelphia: Lippincott Williams and Wilkins; 2006.

6. Lee SJ, Hidler J. Biomechanics of overground vs. treadmill walking in healthy individuals. J Appl Physiol. 2008;104(3):747-55.

7. Monteiro FF. Effect of treadmill-based gait training on the stationary balance. Arch Med Sci. 2009;5(3):443-9.

8. Marsh AP, Katula JA, Pacchia L. Effect of treadmill and overground walking on function and attitudes in older adults. Med Sci Sports Exerc. 2006;38(6):1157-64.

9. Nusdwinuringtyas N. Exercise training in chronic pulmonary disease. In: Nusdwinuringtyas $\mathrm{N}$, editor: Kumpulan makalah rehabilitasi respirasi. Jakarta: Departemen Rehabilitasi Medik RS Dr. Cipto Mangunkusumo; 2006. p. 61-77.

10. Hayes TL, Hagler S, Austin D, Kaye J, Pavel M. Unobtrusive assessment of walking speed in the home using inexpensive PIR sensors. Conf Proc IEEE Eng Med Biol Soc. 2009:7248-51.

11. Peters DM, Fritz SL, Krotish DE. Assessing the reliability and validity of a shorter walk test compared with the 10-meter walk test for measurements of gait speed in healthy, older adults. J Geriatr Phys Ther. 2012;36(1):24-30.

12. Kauffman IL, Barr J, Morran M. Geriatric rehabilitation manual. 2nd ed. China: Elsevier,
Churchill Livingstone; 2007.

13. Raj R. One hundred-foot walk test for functional assessment of clinic patients. Am J Med Sci. 2009;338(5):361-7.

14. Novaes RD, Miranda AS, Dourado VZ. Usual gait speed assessment in middle-aged and elderly Brazilian subjects. Rev Bras Fisioter. 2011;15(2):17-22.

15. Callisaya ML, Blizzard L, Schmidt MD, McGinley JL, Srikanth VK. Sex modifies the relationship between age and gait: a population-based study of older adults. J Gerontol Biol Sci Med Sci. 2008;63(2):165-70.

16. Magdalena IT. Sex-specific correlates of walking speed in a wide age-ranged population. J Gerontol B Psychol Sci Soc Sci. 2010;65B(2):174-84.

17. Riley P, Paolini G, Della CU, Paylo K, Kerrigan D. A kinematic and kinetic comparison of over-ground and treadmill walking in healthy subjects. Gait Posture. 2007;26(1):17-24.

18. Tulchin K, Orendurff M, Karol L. A comparison of multi-segment foot kinematics during level over-ground treadmill walking. Gait Posture. 2010;31(1):104-8.

19. Sohn RH, Swang SH, Kim YH. Comparison of motion analysis and energy expenditure between treadmill and overground walking. Proceedings of International Federation for Medical and Biological Engineering; 2009 Nov 30-Dec 1; Italy. Italy: IFMBE; 2009.

20. Wert DM, Brach J, Perera S, Van Swearingen JM. Gait biomechanics, spatial and temporal characteristics, and the energy cost of walking in older adults with impaired mobility. J Phys Ther. 2010;90(7):977-85. 